\title{
Polyphenolic composition of grape stem extracts affects antioxidant activity in endothelial and muscle cells
}

\author{
NIKOLAOS GOUTZOURELAS ${ }^{1}$, DIMITRIOS STAGOS ${ }^{1}$, YPATIOS SPANIDIS ${ }^{1}$, MARIA LIOSI ${ }^{1}$, \\ ANNA APOSTOLOU ${ }^{2}$, ALEXANDROS PRIFTIS ${ }^{1}$, SERKO HAROUTOUNIAN ${ }^{2}$, DEMETRIOS A. SPANDIDOS ${ }^{3}$, \\ ARISTIDIS M. TSATSAKIS ${ }^{4}$ and DEMETRIOS KOURETAS ${ }^{1}$ \\ ${ }^{1}$ Department of Biochemistry and Biotechnology, University of Thessaly, 41221 Larissa; \\ ${ }^{2}$ Laboratory of Nutrition Physiology and Feeding, Agricultural University of Athens, 11855 Athens; \\ ${ }^{3}$ Laboratory of Clinical Virology, Medical School, University of Crete, 71409 Heraklion; ${ }^{4}$ Department of Forensic Sciences \\ and Toxicology, Medical School, University of Crete, 71003 Heraklion, Greece
}

Received July 10, 2015; Accepted August 12, 2015

DOI: $10.3892 / \mathrm{mmr} .2015 .4216$

\begin{abstract}
The aim of the present study was the assessment of the antioxidant effects of polyphenolic extracts derived from the stems of three Greek grape varieties (Moshomayro, Mavrotragano and Mandilaria) in endothelial (EA.hy926) and muscle $(\mathrm{C} 2 \mathrm{C} 12)$ cells. We also investigated the effects of the polyphenolic composition on the antioxidant effects of the grape stem extracts. For this purpose, the endothelial and muscle cells were treated with low non-cytotoxic concentrations of the extracts for $24 \mathrm{~h}$ in order to assess the effects of the extracts on cellular redox status using oxidative stress biomarkers. The oxidative stress markers were thiobarbituric acid reactive substances (TBARS), protein carbonyl (CARB) levels, reactive oxygen species (ROS) levels and glutathione (GSH) levels. The results revealed that treatment of the EA.hy926 cells with
\end{abstract}

Correspondence to: Professor Demetrios Kouretas, Department of Biochemistry and Biotechnology, University of Thessaly, Ploutonos 26 and Aiolou St., 41221 Larissa, Greece

E-mail: dkouret@uth.gr

Abbreviations: ABTS, 2,2'-azino-bis(3-ethylbenzothiazoline-6sulphonic acid); CARB, protein carbonyl; DMEM, Dulbecco's modified Eagle's medium; DCF-DA, 2,7-dichlorofluorescein diacetate; DNPH, 2,4-dinitrophenylhydrazine; DPPH, 2,2-diphenyl-1-picrylhydrazyl; EDTA, ethylenediaminetetraacetic acid; FBS, fetal bovine serum; GSH, glutathione; $\mathrm{H}_{2} \mathrm{O}_{2}$, hydrogen peroxide; $\mathrm{HRP}$, horseradish peroxidase; NADH, 2-deoxyribose, nicotinamide adenine dinucleotide; NBT, nitroblue tetrazolium; $\mathrm{O}_{2}{ }^{\circ}$, superoxide radical; $\mathrm{OH}^{*}$, hydroxyl radical; PBS, phosphate-buffered saline; PMS, phenazine methosulfate; ROO*, peroxyl radical; ROS, reactive oxygen species; TBA, thiobarbituric acid; TBARS, thiobarbituric acid reactive substances; TCA, trichloroacetic acid; TPC, total polyphenolic content

Key words: antioxidant, oxidative stress, polyphenols, grape stem extracts, endothelial cells, muscle cells, flow cytometry
Mandilaria extract significantly decreased the TBARS levels by $14.8 \%$ and the CARB levels by $25.9 \%$, while it increased the GSH levels by $15.8 \%$ compared to the controls. Moreover, treatment of the EA.hy926 cells with Mavrotragano extract significantly increased the GSH levels by $20.2 \%$, while it significantly decreased the TBARS and CARB levels by $12.5 \%$ and $16.6 \%$, respectively. Treatment of the $\mathrm{C} 2 \mathrm{C} 12$ cells with Mandilaria extract significantly decreased the TBARS levels by $47.3 \%$, the CARB levels by $39.0 \%$ and the ROS levels by $21.8 \%$, while it increased the GSH levels by $22.6 \%$ compared to the controls. Moreover, treatment of the $\mathrm{C} 2 \mathrm{C} 12$ cells with Mavrotragano significantly decreased the TBARS, CARB and ROS levels by $36.2 \%, 35.9 \%$ and $16.5 \%$, respectively. In conclusion, to the best of our knowledgel, our results demonstrate for the first time that treatment with grape stem extracts at low concentrations improves the redox status of endothelial and muscle cells. Thus, grape stem extracts may be used for developing antioxidant food supplements or biofunctional foods. However, it was also found that the polyphenolic composition of grape stem extracts affects their antioxidant capacity. For example, the results suggested that trans-resveratrol, gallic acid, (+)-catechin, ferulic acid, caffeic acid, quercetin, coumaric acid and kaempferol may be essential for the antioxidant activity of grape stem extracts.

\section{Introduction}

Reactive oxygen species (ROS) are chemically reactive molecules containing oxygen. ROS include free radicals, such as superoxide radical $\left(\mathrm{O}_{2}{ }^{\circ}\right)$, hydroxyl radical $\left(\mathrm{OH}^{\circ}\right)$ and peroxyl radical $\left(\mathrm{ROO}^{\circ}\right)$, as well as non-radical species, such as hydrogen peroxide $\left(\mathrm{H}_{2} \mathrm{O}_{2}\right)$, which are products of normal metabolism, inflammation, phagocytosis, intracellular signaling, cell proliferation, apoptosis or other physiological processes $(1,2)$. Oxidative stress is defined as an imbalance between the production of free radicals and the ability of the organism to counteract or detoxify their harmful effects through neutralization by antioxidants (1). As free radicals are very reactive species, their overproduction during oxidative stress can cause damage to all 
biological macromolecules, such as DNA, proteins and lipids, thus leading to cell damage and subsequently, to the manifestation of pathological conditions (1).

Oxidative stress occurs frequently in muscle tissue. In particular, during intense exercise, there is a high rate of $\mathrm{O}_{2}$ consumption in skeletal muscle that can cause incomplete $\mathrm{O}_{2}$ reduction and electron leakage from the electron transfer chain, leading to the generation of ROS and oxidative stress, that in turn result in muscle fatigue, cell damage and apoptosis (2-4).

Furthermore, oxidative stress-induced damage of the vascular endothelium is one of the most important factors of cardiovascular diseases (5-7). For example, oxidative stress in endothelial cells induces acute and chronic phases of leukocyte adhesion to the endothelium $(8,9)$. In addition, the interaction between ROS and nitric oxide sets off a vicious circle which results in further endothelial activation and inflammation (5). Moreover, ROS, such as $\mathrm{H}_{2} \mathrm{O}_{2}$ can diffuse throughout endothelial cells and react with cysteine groups in proteins to modify their function (10). Thus, under conditions of oxidative stress, endothelial cells can lose integrity, progress to senescence and detach into the circulation (11).

However, every living organism has antioxidant mechanisms to counteract oxidative stress (1). Apart from the endogenous antioxidant mechanisms, the supplementation of antioxidants through diet may be used to reduce the detrimental effects of oxidative stress on human health as suggested by our previous studies $(12,13)$. Some of the most well known food sources of antioxidants are grapes and wine (14). Our research group has conducted several studies on the antioxidant properties of grapes which are attributed mainly to their polyphenolic content (15-21). We have also conducted a series of studies on the antioxidant activity of extracts from grape stems, a by-product of the winemaking process which has been little investigated $(15,22-25)$. For example, in one of our previous studies, we demonstrated that grape stem extracts are rich in bioactive polyphenols (e.g., flavonoids, stilbenes and phenolic acids) (22) and exhibit strong free radical scavenging activity in vitro (15).

Thus, the aim of the present study was firstly to examine the antioxidant effects of stem extracts from three Greek grape (Vitis vinifera) varieties (i.e., Mandilaria, Mavrotragano and Moshomavro) at a cellular level, particularly in human umbilical vein endothelial EA.hy926 and C2C12 muscle cells. Moreover, since the polyphenolic composition has been shown to affect the antioxidant activity of wine and grape seed extracts $(26,27)$, we also investigated whether the polyphenolic composition of grape stem extracts affects their antioxidant capacity. Grape stem extracts may be used as antioxidant food supplements for reducing the oxidative stress-induced detrimental effects on human health, and thus the understanding of the mechanisms through which they exert their bioactivities is of particular importance.

\section{Materials and methods}

Chemicals, reagents and culture medium. Dulbecco's modified Eagle's medium (DMEM), fetal bovine serum (FBS), phosphate-buffered saline (PBS) and trypsin were purchased from Gibco (Grand Island, NY, USA). Ethylenediaminetetraacetic acid (EDTA), 2,2'-azino-bis (3-ethylbenzothiazoline-6-sulfonic acid), diammonium salt (ABTS), horseradish peroxidase (HRP), 2,2-diphenyl-1-picrylhydrazyl (DPPH), ferric chloride, 2-deoxyribose, nicotinamide adenine dinucleotide (NADH), nitroblue tetrazolium (NBT), phenazine methosulfate (PMS), mercury orange and 2,7-dichlorofluorescein diacetate (DCFDA) were obtained from Sigma-Aldrich (St. Louis, MO, USA). Trichloroacetic acid (TCA) and 2-thiobarbituric acid (TBA) were purchased from Merck (Darmstadt, Germany) and potassium ferricyanide was obtained from AppliChem (Dresden, Germany). The cell proliferation kit II (XTT) was purchased from Roche Diagnostics (Mannheim, Germany).

Preparation of the extracts. The stem extracts were prepared from the Greek grape varieties, Mandilaria, Mavrotragano and Moshomavro. The isolation of the extracts was performed as described in a previous study of ours (15). In brief, $50 \mathrm{~g}$ of dried sample (powdered grape stems) were poured into a $200 \mathrm{ml}$ mixture of methanol $(\mathrm{MeOH}) / \mathrm{H}_{2} \mathrm{O} / 1.0 \mathrm{~N} \mathrm{HCl}(90: 9.5: 0.5 \mathrm{v} / \mathrm{v})$ and sonicated in an ultrasonic bath for $10 \mathrm{~min}$. The solvent was separated by filtration, and the remaining solid was re-extracted three additional times, using the same solvent system and procedure. The combined extracts were evaporated under vacuum, resulting in a slurry, which was dissolved in $30 \mathrm{ml}$ of $\mathrm{MeOH} /$ $\mathrm{H}_{2} \mathrm{O}$ (1:1) and centrifuged for $10 \mathrm{~min}$ (7,000 rpm). The supernatant liquid was extracted with petroleum ether $(3 \times 30 \mathrm{ml})$ to remove the lipids and concentrated under a vacuum. The remaining residue was poured into $30 \mathrm{ml}$ of brine and extracted repetitively with ethyl acetate (EtOAc, 4x30 ml). Thus, all sugars remained in the aqueous layer. The combined organic layers were then dried over anhydrous magnesium sulfate and evaporated under a vacuum. The remaining solid was weighed and dissolved in $\mathrm{MeOH}$ to $1 \mathrm{mg} / \mathrm{ml}$, and membrane filtered $(0.45 \mu \mathrm{m})$. To avoid polyphenol degradation, all of the aforementioned activities were performed in the absence of direct sunlight and at temperatures below $35^{\circ} \mathrm{C}$.

Assessment of the polyphenolic composition of the extracts. The total polyphenolic content (TPC) of the extracts was identified by the Folin-Ciocalteu method as previously described (15). Briefly, a $100 \mu \mathrm{l}$ sample of extract was added to a $10 \mathrm{ml}$ flask containing $6 \mathrm{ml}$ of deionized water. One milliliter of FolinCiocalteu reagent was added to the mixture, and the flask was stoppered and allowed to stand at room temperature for $3 \mathrm{~min}$. A $1.5 \mathrm{ml}$ portion of $20 \% \mathrm{Na}_{2} \mathrm{CO}_{3}$ was added and the solution was diluted to the desire volume $(10 \mathrm{ml})$ with deionized water. The absorbance was measured at $725 \mathrm{~nm}$ versus a blank after $2 \mathrm{~h}$ at room temperature. The results are expressed as gallic acid equivalents using the standard curve (absorbance versus concentration) prepared from authentic gallic acid.

The polyphenolic composition of the extracts was assessed by high pressure liquid chromatography (HPLC) as previously described (15). Specifically, HPLC was carried out on a Hewlett Packard HP1100 system equipped with a quaternary pump and degasser. The column used was a Kromasil C18 column (250 mm x $4.6 \mathrm{~mm}$, particle size $5 \mu \mathrm{m})$ with a guard column of the same material $(8 \times 4 \mathrm{~mm})$. Injection was by means of a Rheodyne injection valve (model 7725I) with a $20 \mu$ l fixed loop. For the chromatographic analyses, HPLC grade water was prepared using a Milli-Q system, whereas all HPLC solvents were filtered prior to use through cellulose acetate membranes 
of $0.45 \mu \mathrm{m}$ pore size. Chromatographic data were acquired and processed using Chemstation software. More specifically, the analysis was carried out at $30^{\circ} \mathrm{C}$ (maintained by a column thermostat) using samples of $20 \mu$, which were directly injected by means of a Rheodyne injection valve (model 7725I). The gradient eluted consisted of solvent A (obtained by the addition of $3 \%$ acetic acid in $2 \mathrm{mM}$ sodium acetate aqueous solution) and solvent $\mathrm{B}$ (acetonitrile, $\mathrm{CH}_{3} \mathrm{CN}$ ). Run time was set at $70 \mathrm{~min}$ with a constant flow rate at $1.0 \mathrm{ml} / \mathrm{min}$ in accordance with the following gradient time table: at zero time, $95 \% \mathrm{~A}$ and $5 \% \mathrm{~B}$; after $45 \mathrm{~min}$, the pumps were adjusted to $85 \% \mathrm{~A}$ and $15 \% \mathrm{~B}$; at $60 \mathrm{~min}, 65 \% \mathrm{~A}$ and $35 \% \mathrm{~B}$; at $65 \mathrm{~min}, 50 \% \mathrm{~A}$ and $50 \% \mathrm{~B}$; and finally at $70 \mathrm{~min}, 100 \% \mathrm{~B}$. This routine was followed by a 30 -min equilibration period with the zero time mixture prior to injection of the next sample. The analysis was monitored at 280,320 , and $360 \mathrm{~nm}$ simultaneously. Three replicate experiments were carried out for each sample examined. Peaks were identified by comparing their retention time and UV-vis spectra with the reference compounds, and data were quantified using the corresponding curves of the reference compounds as standards. All standards were dissolved in methanol.

Cell culture conditions. The EA.hy926 cells were a gift from Professor Koukoulis (University of Thessaly, Larissa, Greece) and the $\mathrm{C} 2 \mathrm{C} 12$ muscle cells were a gift from Professor Koutsilieris (National and Kapodistrian University of Athens, Athens, Greece). All cells were cultured in normal DMEM, containing 10\% (v/v) FBS, 2 mM L-glutamine, $100 \mathrm{U} / \mathrm{ml}$ of penicillin and $100 \mathrm{U} / \mathrm{ml}$ of streptomycin (all from Gibco, Paisley, UK) in plastic disposable tissue culture flasks at $37^{\circ} \mathrm{C}$ in $5 \%$ carbon dioxide.

Cell viability assay. The effects of the grape stem extracts on cell viability were assessed using the XTT assay kit (Roche Diagnostics) as previously described (21). Briefly, the cells were subcultured in a 96-well plate with $1 \times 10^{4}$ cells per well in DMEM. After $24 \mathrm{~h}$ of incubation, the cells were treated with increasing concentrations of the extracts in serum-free DMEM for $24 \mathrm{~h}$. A total of $50 \mu \mathrm{l}$ of XTT test solution, which was prepared by mixing $50 \mu \mathrm{l}$ of XTT-labeling reagent with $1 \mu \mathrm{l}$ of electron coupling reagent, was then added to each well. After $4 \mathrm{~h}$ of incubation, the absorbance was measured at $450 \mathrm{~nm}$ and also at $690 \mathrm{~nm}$ as a reference wavelength in a Bio-Tek ELx800 microplate reader (Winooski, VT, USA). DMEM serum-free medium was used as a negative control. In addition, the absorbance of each grape extract concentration alone in DMEM serum-free medium and XTT test solution was tested at $450 \mathrm{~nm}$. The absorbance values shown by the grape extracts alone were subtracted from those derived from cells treated with the grape extracts. Data were calculated as a percentage of inhibition using the following formula: inhibition $(\%)=[(\mathrm{OD}$ control - OD sample)/OD control] x100, where OD control and OD sample indicate the optical density of the negative control and the tested substances, respectively. All experiments were carried out in triplicate and at least on 2 separate occasions.

DPPH radical scavenging assay. The DPPH radical scavenging activity of the grape stem extracts was evaluated as previously described (15). Briefly, a $1.0 \mathrm{ml}$ freshly prepared methanolic solution of DPPH radical $(100 \mu \mathrm{M})$ was mixed with the test extract solution at different concentrations. The contents were vigorously mixed, incubated at room temperature in the dark for $20 \mathrm{~min}$ and the absorbance was read at $517 \mathrm{~nm}$. In each experiment, the test extract alone in methanol was used as a blank and DPPH radical alone in methanol was used as a control. The percentage of inhibition of DPPH radical by the tested extracts was calculated according to the following equation: inhibition $(\%)=[(\mathrm{A}$ control $-\mathrm{A}$ sample $) / \mathrm{A}$ control $] \mathrm{x} 100$, where A control and A sample are the absorbance values of the control and the test sample, respectively. Moreover, in order to compare the radical scavenging efficiency of the extracts, the $\mathrm{IC}_{50}$ value showing the concentration that caused $50 \%$ scavenging of DPPH radicals was calculated from the graph plotted inhibition percentage against extract concentration. All experiments were carried out in triplicate and at least on 2 separate occasions.

ABTS $^{*+}$ radical scavenging assay. $\mathrm{ABTS}^{*+}$ radical scavenging activity was measured as described previously (15). In brief, $\mathrm{ABTS}^{\circ+}$ radicals were produced by mixing $2 \mathrm{mM}$ ABTS with $30 \mu \mathrm{M} \mathrm{H}_{2} \mathrm{O}_{2}$ and $6 \mu \mathrm{M}$ HRP enzyme in $50 \mathrm{mM}$ phosphate-buffered saline (PBS, $\mathrm{pH}$ 7.5). Immediately following the addition of the HRP enzyme, the contents were vigorously mixed, incubated at room temperature in the dark and the reaction was monitored at $730 \mathrm{~nm}$ until stable absorbance was obtained. Subsequenlty, $10 \mu \mathrm{L}$ of different extract concentrations were added to the reaction mixture and the decrease in absorbance at $730 \mathrm{~nm}$ was determined. In each experiment, the test extract alone containing $1 \mathrm{mM}$ ABTS and $30 \mu \mathrm{M} \mathrm{H}_{2} \mathrm{O}_{2}$ in $50 \mathrm{mM}$ (PBS, pH 7.5) was used as a blank, while the formed ABTS ${ }^{++}$ radical solution alone with $10 \mu \mathrm{L} \mathrm{H}_{2} \mathrm{O}$ was used as a control. The inhibition percentage and the $\mathrm{IC}_{50}$ values were determined as described above for the DPPH method. All experiments were carried out in triplicate and at least on 2 separate occasions.

Reducing power assay. Reducing power was determined as previously described (28). Briefly, the extracts were dissolved in phosphate buffer ( $0.2 \mathrm{M}, \mathrm{pH} 6.6)$ at different concentrations. An aliquot $(2.5 \mathrm{ml})$ of the sample solution was added to $2.5 \mathrm{ml}$ of potassium ferricyanide $(1 \%)$ and incubated at $50^{\circ} \mathrm{C}$ for $20 \mathrm{~min}$. The samples were cooled on ice for $5 \mathrm{~min}$. Subsequenlty, $2.5 \mathrm{ml}$ TCA $(10 \%)$ were added and the samples were centrifuged at $3,000 \mathrm{rpm}$ for $10 \mathrm{~min}$ at $25^{\circ} \mathrm{C}$. To the supernatant $(2.5 \mathrm{ml})$, $2.5 \mathrm{ml}$ deionized water and $500 \mu \mathrm{l}$ ferric chloride $(0.1 \%)$ were added and the samples were incubated at room temperature for $10 \mathrm{~min}$. The absorbance was measured at $700 \mathrm{~nm}$. All experiments were carried out in triplicate and at least on 2 separate occasions.

Treatment of EA.hy926 and C2C12 cells with the grape stem extracts. The cells were seeded in culture flasks and incubated for $24 \mathrm{~h}$. The medium was then removed and replaced with serumfree medium containing the grape extracts at non-cytotoxic concentrations. Since one of the main purposes of the study was to examine the effects of the polyphenolic composition on the antioxidant activity of the extracts, the selected concentrations for all three tested extracts had the same total polyphenolic content and were expressed as ' $\mu \mathrm{g}$ of polyphenols $/ \mathrm{ml}$ '. Thus, the selected concentrations used were $0.20 \mu \mathrm{g}$ of polyphenols $/ \mathrm{ml}$ for the EA.hy 926 cells and $0.95 \mu \mathrm{g}$ of polyphenols $/ \mathrm{ml}$ for the 
$\mathrm{C} 2 \mathrm{C} 12$ cells. The cells were treated with the extracts for $24 \mathrm{~h}$ and were then trypsinized, collected and centrifuged twice at $300 \mathrm{x}$ g for $10 \mathrm{~min}$ at $5^{\circ} \mathrm{C}$. At the end of the first centrifugation, the supernatant fluid was discarded and the cellular pellet was resuspended in PBS. After the second centrifugation, the cell pellet was collected and used for measuring the levels of the oxidative stress markers, glutathione (GSH), ROS, thiobarbituric acid reactive substances (TBARS) and protein carbonyl (CARB).

Flow cytometric analysis of GSH and ROS levels. The intracellular GSH and ROS levels were assessed by flow cytometry using mercury orange and DCF-DA, respectively as described previously (21). In particular, the fluorescent mercury orange binds directly to GSH, whilst DCF-DA within cells is deacetylated by esterases, and is further converted to fluorescent DCF by the oxidative action of ROS. A $400 \mu \mathrm{M}$ stock solution of mercury orange was prepared in acetone and stored at $4^{\circ} \mathrm{C}$, while a fresh $400 \mu \mathrm{M}$ stock solution of DCF-DA was prepared in methanol. To assess the GSH and ROS levels, the cells were resuspended in PBS at $1 \times 10^{6}$ cells per $\mathrm{ml}$ and incubated in the presence of mercury orange $(40 \mu \mathrm{M})$ or DCF-DA $(10 \mu \mathrm{M})$ in the dark at $37^{\circ} \mathrm{C}$ for $30 \mathrm{~min}$. The cells were then washed, resuspended in PBS and submitted to flow cytometric analysis using a FACScan flow cytometer (Becton-Dickinson, Franklin Lakes NJ, USA) with excitation and emission wavelengths at 488 and $530 \mathrm{~nm}$ for ROS, and at 488 and $580 \mathrm{~nm}$ for GSH. In addition, forward angle and right angle light scattering indicating the cell size and cell internal complexity, respectively were measured. The cells were analysed at a flow rate of 1,000 events per second. Analyses were performed on 10,000 cells per sample and fluorescence intensities were measured on a logarithmic scale of 4 decades of the log of fluorescence. Data was analysed using BD Cell Quest software (Becton-Dickinson). Each experiment was repeated at least 3 times.

Assessment of TBARS levels by spectrophotometry. For the determination of TBARS levels, the cells were resuspended in PBS at $1 \times 10^{6}$ cells $/ \mathrm{ml}$. Subsequently, a slightly modified assay as desribed in the study by Keles et al (29) was used as previously described (21). A total of $400 \mu \mathrm{l}$ of cell suspension or $400 \mu \mathrm{l}$ of PBS for the blank was mixed with $500 \mu \mathrm{l}$ of $35 \%$ TCA and $500 \mu \mathrm{l}$ of tris(hydroxymethyl)aminomethane hydrochloride (Tris-HCl) (200 mM, pH 7.4) and incubated for $10 \mathrm{~min}$ at room temperature. Afterwards, $1 \mathrm{ml}$ solution consisting of $2 \mathrm{M} \mathrm{Na}_{2} \mathrm{SO}_{4}$ and $55 \mathrm{mM}$ thiobarbituric acid was added and the samples were incubated at $95^{\circ} \mathrm{C}$ for $45 \mathrm{~min}$. The samples were cooled on ice for $5 \mathrm{~min}$ and vortexed following the addition of $1 \mathrm{ml}$ of $70 \%$ TCA. The samples were then centrifuged at $15,000 \mathrm{x} \mathrm{g}$ for $3 \mathrm{~min}$ and the absorbance of the supernatant was read at $530 \mathrm{~nm}$. The assay requires $>30 \mu \mathrm{g}$ absolute amount of protein in the test sample. The total protein concentration in the cell suspension was assayed using a Bradford reagent from Sigma-Aldrich. The calculation of the TBARS concentration was based on the molar extinction co-efficient of malondialdehyde. Each experiment was repeated at least 3 times.

Assessment of CARB levels by spectrophotometry. For the determination of CARB levels, the cells were resuspended in PBS at $1 \times 10^{6}$ cells $/ \mathrm{ml}$ and then lysed by sonication.
Subsquently, a modified method as described in the study by Patsoukis et al (30) was used as previously described (21). In brief, $200 \mu \mathrm{L}$ of $20 \%$ TCA were added to $200 \mu 1$ of cell lysate, and this mixture was incubated in an ice bath for $15 \mathrm{~min}$ and centrifuged at $15,000 \mathrm{x}$ g for $5 \mathrm{~min}$ at $4^{\circ} \mathrm{C}$. The supernatant fraction was discarded. In addition, $500 \mu \mathrm{l}$ of $10 \mathrm{mM}$ 2,4-dinitrophenylhydrazine (DNPH; in $2.5 \mathrm{~N} \mathrm{HCl}$ ) for the sample or $500 \mu \mathrm{l}$ of $2.5 \mathrm{~N} \mathrm{HCl}$ for the blank were added to the pellet. The samples were incubated in the dark at room temperature for $1 \mathrm{~h}$, with intermittent mixing every $15 \mathrm{~min}$ and were centrifuged at $15,000 \mathrm{x} \mathrm{g}$ for $5 \mathrm{~min}$ at $4^{\circ} \mathrm{C}$. The supernatant fraction was discarded, and $1 \mathrm{ml}$ of $10 \%$ TCA was added to the pellet which was mixed and centrifuged at $15,000 \mathrm{x} \mathrm{g}$ for $5 \mathrm{~min}$ at $4^{\circ} \mathrm{C}$. The supernatant fraction was discarded and $1 \mathrm{ml}$ of ethanolethyl acetate (1:1 v/v) was added, vortexed and centrifuged at $15,000 \mathrm{x} \mathrm{g}$ for $5 \mathrm{~min}$ at $4^{\circ} \mathrm{C}$. This washing step was repeated twice. The supernatant fraction was discarded, and $1 \mathrm{ml}$ of $5 \mathrm{M}$ urea $\left(\mathrm{pH}\right.$ 2.3) was added, vortexed and incubated at $37^{\circ} \mathrm{C}$ for $15 \mathrm{~min}$. The samples were centrifuged at 15,000 x g for $3 \mathrm{~min}$ at $4^{\circ} \mathrm{C}$, and the absorbance was read at $375 \mathrm{~nm}$. The calculation of the protein carbonyl concentration was based on the molar extinction co-efficient of DNPH. The assay requires $>30 \mu \mathrm{g}$ absolute amount of protein in the test sample. The total plasma protein concentration was evaluated using Bradford assay. Each experiment was repeated at least 3 times.

Statistical analysis. Data were analyzed by one-way ANOVA followed by Tukey's test for multiple pairwise comparisons. The level of statistical significance was set at $\mathrm{p}<0.05$. For all statistical analyses, SPSS software, version 13.0 (SPSS Inc., Chicago, IL, USA) was used. Data are presented as the means \pm SEM.

\section{Results}

Polyphenolic composition of the grape stem extracts. The TPC and the polyphenolic composition of the extracts were identified by HPLC and are presented in Table I. The TPC values were similar between the three extracts and ranged from 357 to $378 \mathrm{mg}$ gallic acid/g dried extract. These TPC values were similar to those observed in one of our previous studies (15). Moreover, as we have previously found in other grape stem extracts $(15,22)$, the extracts contained different classes of polyphenols, such as phenolic acids (i.e., gallic acid, caffeic acid, coumaric acid, ferulic acid and syringic acid), flavanols [(+)-catechin and (-)-epicatechin], flavonols (quercetin, rutin and kaempferol) and stilbenes (trans-resveratrol) (Table I). The amounts of some polyphenols did not differ significantly between the three extracts. These polyphenols were syringic acid (13.60-17.44 mg/g dried extract), (+)-catechin (8.49-12.49 mg/g dried extract) and rutin (12.06-15.93 $\mathrm{mg} / \mathrm{g}$ dried extract) (Table I). However, the amounts of the other polyphenols presented marked differences between the three tested extracts. Thus, their ranges were 3.6-fold for gallic acid (7.39-26.96 mg/g dried extract), 4.2-fold for caffeic acid (0.54-2.32 mg/g dried extract), 1.9-fold for (-)-epicatechin (9.83-19.13 mg/g dried extract), 2.1-fold for coumaric acid $(0.60-1.31 \mathrm{mg} / \mathrm{g}$ dried extract), 3.7-fold for ferulic acid $(0.97-3.59 \mathrm{mg} / \mathrm{g}$ dried extract), 3.5-fold for trans-resveratrol (5.97-21.43 $\mathrm{mg} / \mathrm{g}$ dried extract), 4.3 -fold 
Table I. Polyphenolic composition of the grape stem extracts.

\begin{tabular}{lccc}
\hline Grape variety & Mavrotragano & Mandilaria & Moshomavro \\
\hline Gallic acid & $11.48^{\mathrm{a}}$ & $26.96^{\mathrm{a}}$ & $7.39^{\mathrm{a}}$ \\
Syringic acid & 17.44 & 13.60 & 15.98 \\
Caffeic acid & 0.54 & 2.32 & 0.64 \\
(+)-Catechin & 12.18 & 12.49 & 8.49 \\
(-)-Epicatechin & 19.13 & 9.83 & 12.63 \\
Coumaric acid & 0.75 & 1.31 & 0.60 \\
Ferulic acid & 3.59 & 4.10 & 0.97 \\
Rutin & 15.93 & 12.06 & 14.81 \\
trans-resveratrol & 9.09 & 21.43 & 5.97 \\
Quercetin & 3.94 & 17.33 & 8.01 \\
Kaempferol & 0.74 & 3.63 & 1.83 \\
TPC & 357 & 378 & 373
\end{tabular}

${ }^{\mathrm{a}} \mathrm{All}$ values are $\mathrm{mg} / \mathrm{g}$ dried extract. ${ }^{\mathrm{b}} \mathrm{TPC}$, total polyphenolic content as $\mathrm{mg}$ gallic acid/g dried extract.

Table II. Free radical scavenging activity against $\mathrm{DPPH}^{\bullet}$ and $\mathrm{ABTS}^{\bullet+}$ radicals as well as reducing power of grape stem extracts.

\begin{tabular}{lccc}
\hline Grape variety & $\begin{array}{c}\mathrm{DPPH}^{\bullet \mathrm{a}} \\
\mathrm{IC}_{50}{ }^{\mathrm{b}}\end{array}$ & $\begin{array}{c}\mathrm{ABTS}^{\bullet+\mathrm{b}} \\
\mathrm{IC}_{50}{ }^{\mathrm{b}}\end{array}$ & $\begin{array}{c}\text { Reducing power } \\
\mathrm{RP}_{0.5 \mathrm{AU}}^{\mathrm{b}}\end{array}$ \\
\hline Mandilaria & $2.8 \pm 0.2$ & $0.42 \pm 0.08$ & $1.46 \pm 0.12$ \\
Mavrotragano & $3.6 \pm 0.17$ & $0.71 \pm 0.10$ & $1.47 \pm 0.21$ \\
Moshomavro & $6.5 \pm 0.23$ & $0.90 \pm 0.11$ & $2.92 \pm 0.23$
\end{tabular}

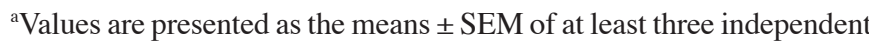
experiments. ${ }^{b} \mathrm{IC}_{50}$ and $\mathrm{RP}_{0.5 \mathrm{AU}}$ values are expressed as ' $\mu \mathrm{g}$ of polyphenols/ml'. DPPH, 2,2-diphenyl-1-picrylhydrazyl; ABTS, 2,2'-azino-bis (3-ethylbenzothiazoline-6-sulfonic acid), diammonium salt.

for quercetin (3.94-17.33 mg/g dried extract) and 4.9-fold for kaempferol (0.74-3.63 mg/g dried extract) (Table I).

Scavenging of free radicals. All the extracts were examined for their free radical scavenging activity. The results revealed that all the extracts scavenged $\mathrm{DPPH}^{\bullet}$ and $\mathrm{ABTS}^{\cdot+}$ radicals in a dosedependent manner at low concentrations (Fig. 1A and B). In order to compare the radical scavenging efficiency of the extracts, the $\mathrm{IC}_{50}$ value indicating the concentration that caused the scavenging of $50 \%$ of $\mathrm{DPPH}^{\circ}$ and $\mathrm{ABTS}^{\circ+}$ radicals was calculated; graphs were created to plot the percentage of radical scavenging capacity against the extract concentration. $\mathrm{The} \mathrm{IC}_{50}$ values calcuated from the DPPH radical scavenging assay were in the following order: Mandilaria extract $(2.8 \pm 0.2 \mu \mathrm{g}$ polyphenols $/ \mathrm{ml})>$ Mavrotragano extract $(3.6 \pm 0.17 \mu \mathrm{g}$ polyphenols $/ \mathrm{ml})>$ Moshomavro extract $(6.5 \pm 0.23 \mu \mathrm{g}$ polyphenols $/ \mathrm{ml})$ (Table II). In the $\mathrm{ABTS}^{\bullet+}$ radical scavenging assay, the order of potency of the extracts according to their $\mathrm{IC}_{50}$ values was: Mandilaria extract $(0.42 \pm 0.08 \mu \mathrm{g}$ polyphenols $/ \mathrm{ml})>$ Mavrotragano extract $(0.71 \pm 0.10 \mu \mathrm{g}$
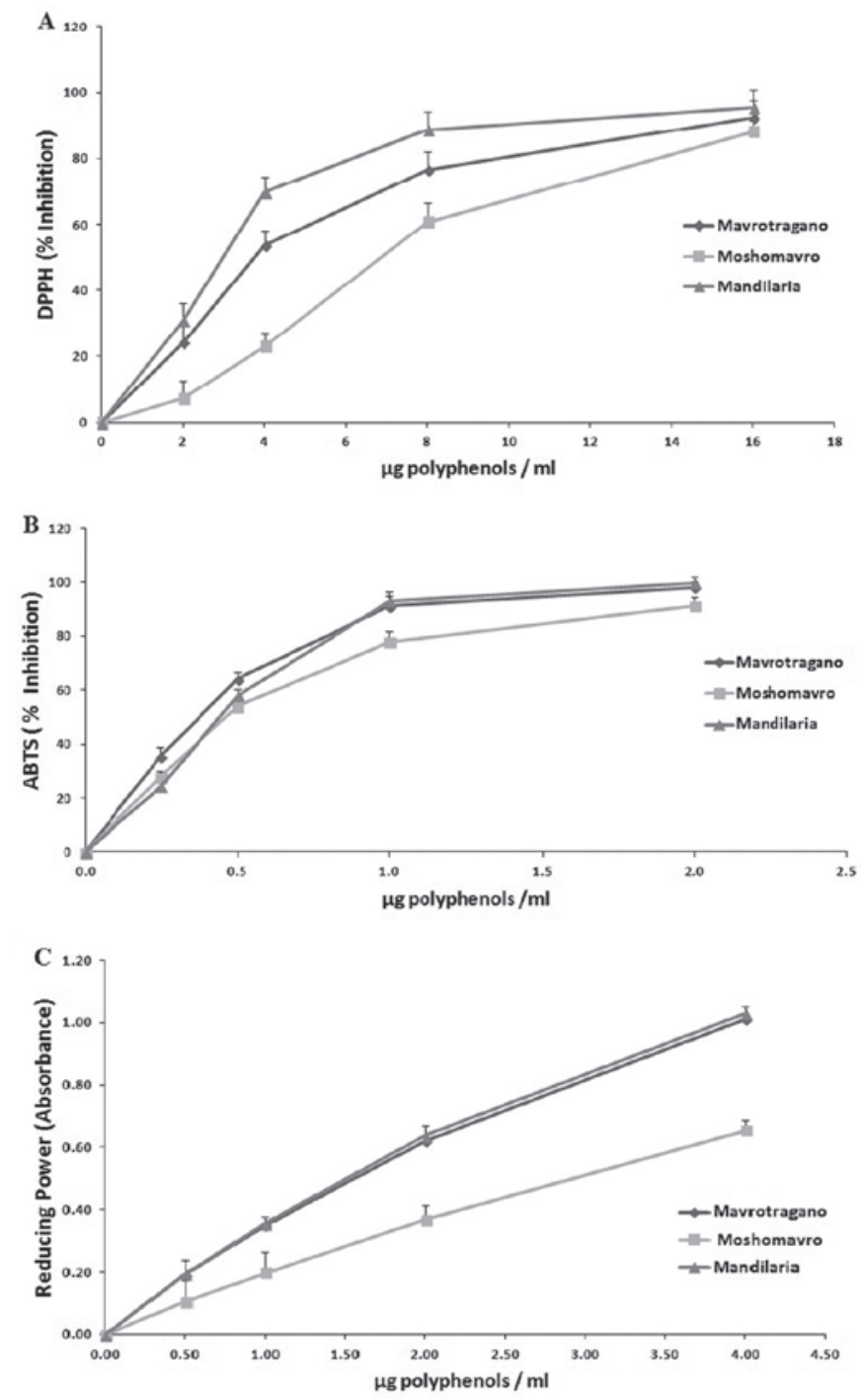

Figure 1. (A) Percentage 2,2-diphenyl-1-picrylhydrazyl (DPPH') radical scavenging activity, (B) percentage 2,2'-azino-bis(3-ethylbenzothiazoline6-sulphonic acid) $\left(\mathrm{ABTS}^{++}\right)$radical scavenging activity and (C) reducing power of grape stem extracts from Mavrotragano, Moshomavro and Mandilaria varieties. Values are presented as the means \pm SEM.

polyphenols $/ \mathrm{ml})>$ Moshomavro extract $(0.90 \pm 0.11 \mu \mathrm{g}$ polyphenols/ml) (Table II).

Reducing power. For the reducing power assay, the $\mathrm{RP}_{0.5 \mathrm{AU}}$, the concentration that produces an absorbance of 0.5 at $700 \mathrm{~nm}$, was determined (Fig. 1C). The $\mathrm{RP}_{0.5 \mathrm{AU}}$ values of the tested extracts were in the following order: Mandilaria extract $(1.46 \pm 0.12 \mu \mathrm{g}$ polyphenols $/ \mathrm{ml})>$ Mavrotragano extract $(1.47 \pm 0.21 \mu \mathrm{g}$ polyphenols $/ \mathrm{ml})>$ Moshomavro extract $(2.92 \pm 0.23 \mu \mathrm{g}$ polyphenols $/ \mathrm{ml}$ ) (Table II).

Effects of grape extracts on the viability of $\mathrm{C} 2 \mathrm{C} 12$ and EA.hy926 cells. XTT assay was used to assess the effects of the grape extracts on the viability of the $\mathrm{C} 2 \mathrm{C} 12$ and EA.hy926 cells in order to select the non-cytotoxic concentrations for use in our experiments. The results revealed that all three extracts exhibited cytotoxicity at concentrations $>1 \mu \mathrm{g}$ polyphenols $/ \mathrm{ml}$ in the EA.hy926 cells and $>4 \mu \mathrm{g}$ polyphenols $/ \mathrm{ml}$ in the $\mathrm{C} 2 \mathrm{C} 12$ 

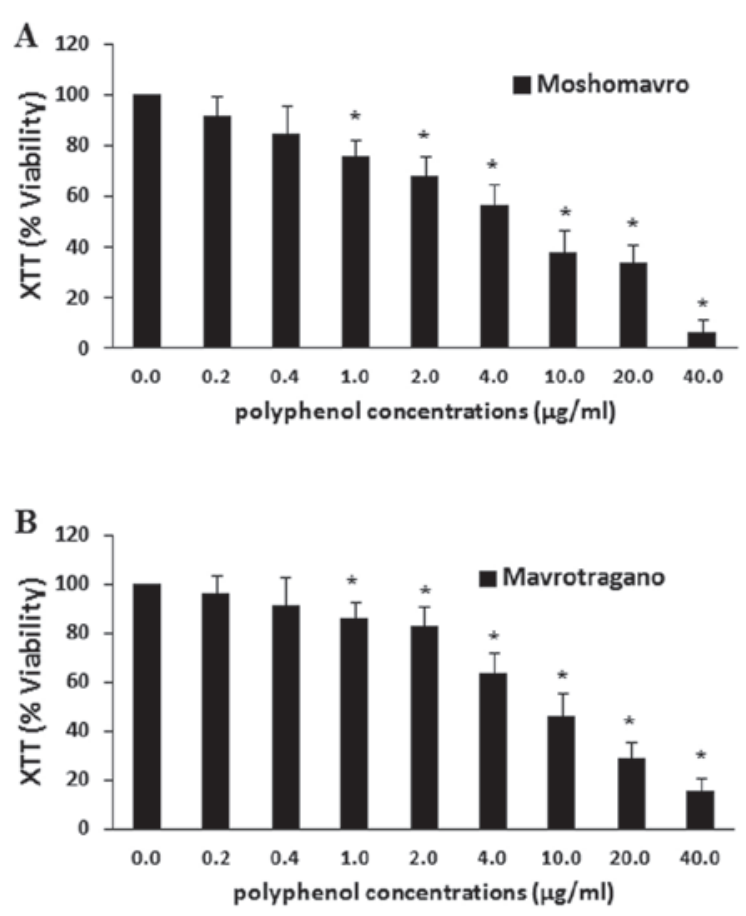

C

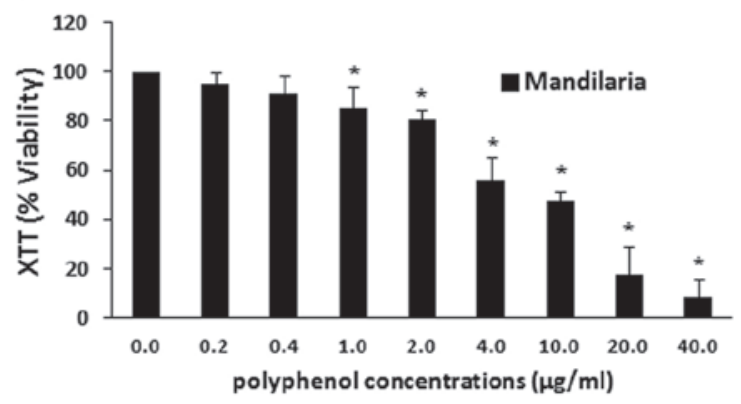

D

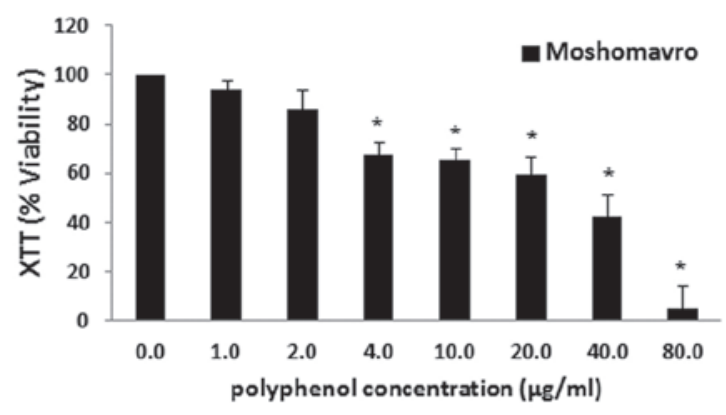

$\mathbf{E}$

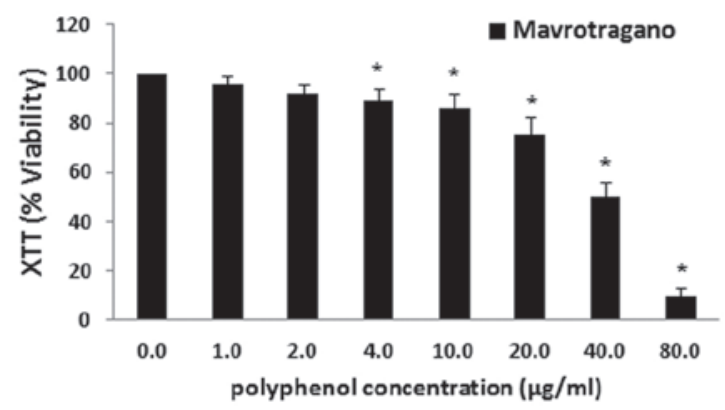

F

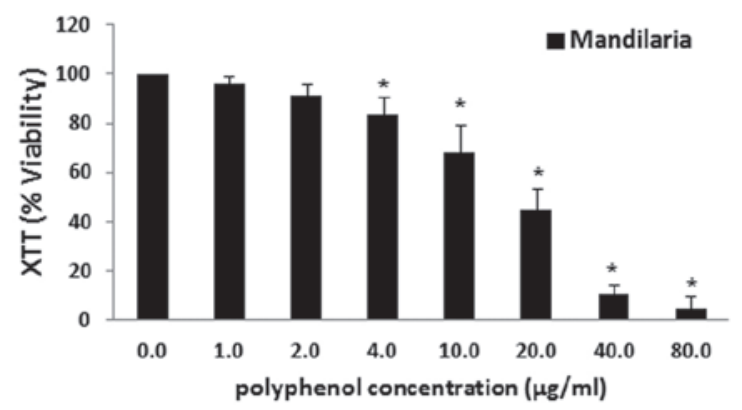

Figure 2. Cell viability following treatment with grape stem extracts from Moshomavro, Mavrotragano and Mandilaria varieties in (A-C) EA.hy926 cells and (D-F) C2C12 cells. The results are presented as the means \pm SEM of three independent experiments carried out in triplicate. ${ }^{*} \mathrm{p}<0.05$ indicates significant difference from the control value.

cells (Fig. 2). Thus, the concentrations that were selected were 0.20 and $0.95 \mu \mathrm{g}$ polyphenols $/ \mathrm{ml}$ for the EA.hy 926 and $\mathrm{C} 2 \mathrm{C} 12$ cells, respectively.

Effects of treatment with grape extracts on the levels of oxidative stress markers in EA.hy926 cells. The levels of oxidative stress markers were measured in order to assess effects of the extracts on the redox status of EA.hy926cells. The ROS and GSH levels were measured by flow cytometry using DCF-DA and mercury orange, respectively. Histograms demonstrating the cell counts versus the fluorescence of the mercury orange or DCF-DA are shown in Fig. 3A and B, respectively. The mean fluorescence intensity values were evaluated using BD CellQuest software and are expressed as a percentage of the controls (untreated cells). None of the tested extracts had any effect on the ROS levels (Fig. 3C). Moreover, the Mavrotragano and Mandilaria extracts significantly increased the GSH levels by $20.2 \pm 1.5$ and $15.8 \pm 4.1 \%$, respectively compared to the controls (Fig. 3C). On the contrary, Moshomavro extract did not affect the GSH levels.

Furthermore, lipid peroxidation and protein oxidation were assessed by measuring spectrophotometrically the levels of TBARS and CARB, respectively (Fig. 3C). Specifically, Mandilaria extract significantly reduced lipid peroxidation by $14.8 \pm 2.3 \%$ compared to the controls, Mavrotragano extract reduced lipid peroxidation by $12.5 \pm 1.9 \%$, while Moshomavro extract had no effect. Similar to lipid peroxidation, treatment with Mandilaria extract exerted the most significant reducing effect on CARB levels by $25.9 \pm 6.3 \%$ (Fig. 3C). Mavrotragano extract reduced the CARB levels by $16.6 \pm 1.3 \%$ and Moshomavro extract did not have any effect on these levels.

Effects of treatment with grape extracts on the levels of oxidative stress markers in C2C12 cells. The histograms demonstrating the cell counts versus the fluorescence of mercury orange or DCF-DA in the C2C12 cells following treatment with the 

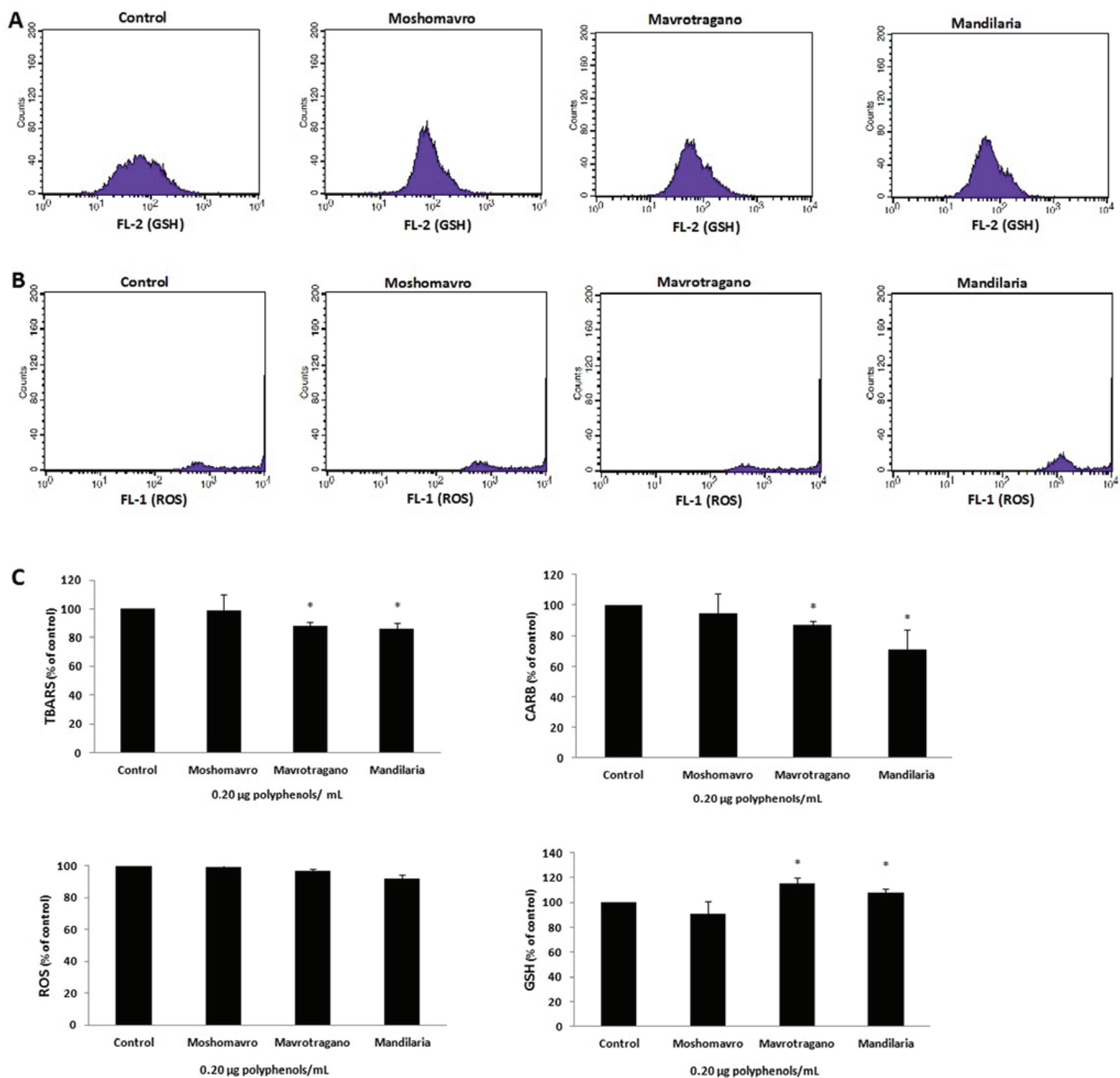

Figure 3. Effects of treatment with grape stem extracts for $24 \mathrm{~h}$ on levels of oxidative stress markers in EA.hy926 cells. (A) The histogram of cell counts versus fluorescence of 10,000 cells analyzed by the flow cytometry for the detection of glutathione (GSH) levels. FL2 represents the detection of fluorescence using 488 and $580 \mathrm{~nm}$ as the excitation and emission wavelength, respectively. (B) The histograms show the cell counts versus fluorescence of 10,000 cells analyzed by the flow cytometry for the detection of reactive oxygen species (ROS) levels. FL1 represents the detection of fluorescence using 488 and $530 \mathrm{~nm}$ as the excitation and emission wavelength, respectively. (C) Effects on ROS, GSH, thiobarbituric acid reactive substances (TBARS) and protein carbonyl (CARB) levels. TBARS and CARB levels were assessed using a spectrophotometer. All values are presented as the means \pm SEM of three independent experiments. "p $<0.05$ indicates significant difference compared to the controls (untreated cells).

grape extracts are shown in Fig. 4A and B, respectively. The Mandilaria and Mavrotragano extracts significantly decreased the ROS levels by $21.8 \pm 2$ and $16.5 \pm 3.7 \%$, respectively, while Moshomavro extract had no effect (Fig. 4C). Finally, Mandilaria extract significantly increased the GSH levels by $22.6 \pm 4.5 \%$ compared to the controls, while the other two extracts did not have any affect on these levels (Fig. 4C).

Moreover, Mandilaria extract significantly reduced the TBARS levels by $47.3 \pm 1.2 \%$, and Mavrotragano extract by $36.2 \pm 9.6 \%$, while Moshomavro extract had no effect compared to the controls in the $\mathrm{C} 2 \mathrm{C} 12$ cells (Fig. 4C). In addition, Mandilaria extract exerted the greatest reducing effect on CARB levels, decreasing them by $39.0 \pm 5.1 \%$ (Fig. 4C). Mavrotragano extract reduced the CARB levels by $35.9 \pm 7.1 \%$ and Moshomavro extract did not have any effect on these levels (Fig. 4C).

\section{Discussion}

Grape extracts and wine have been the center of attention of researchers, demonstrating their beneficial effects on human health (14). For example, food supplements termed as 'grape seed extracts' are consumed worldwide for their beneficial effects on human health. However, the majority of studies on grapes refer to extracts from seeds, skins and 

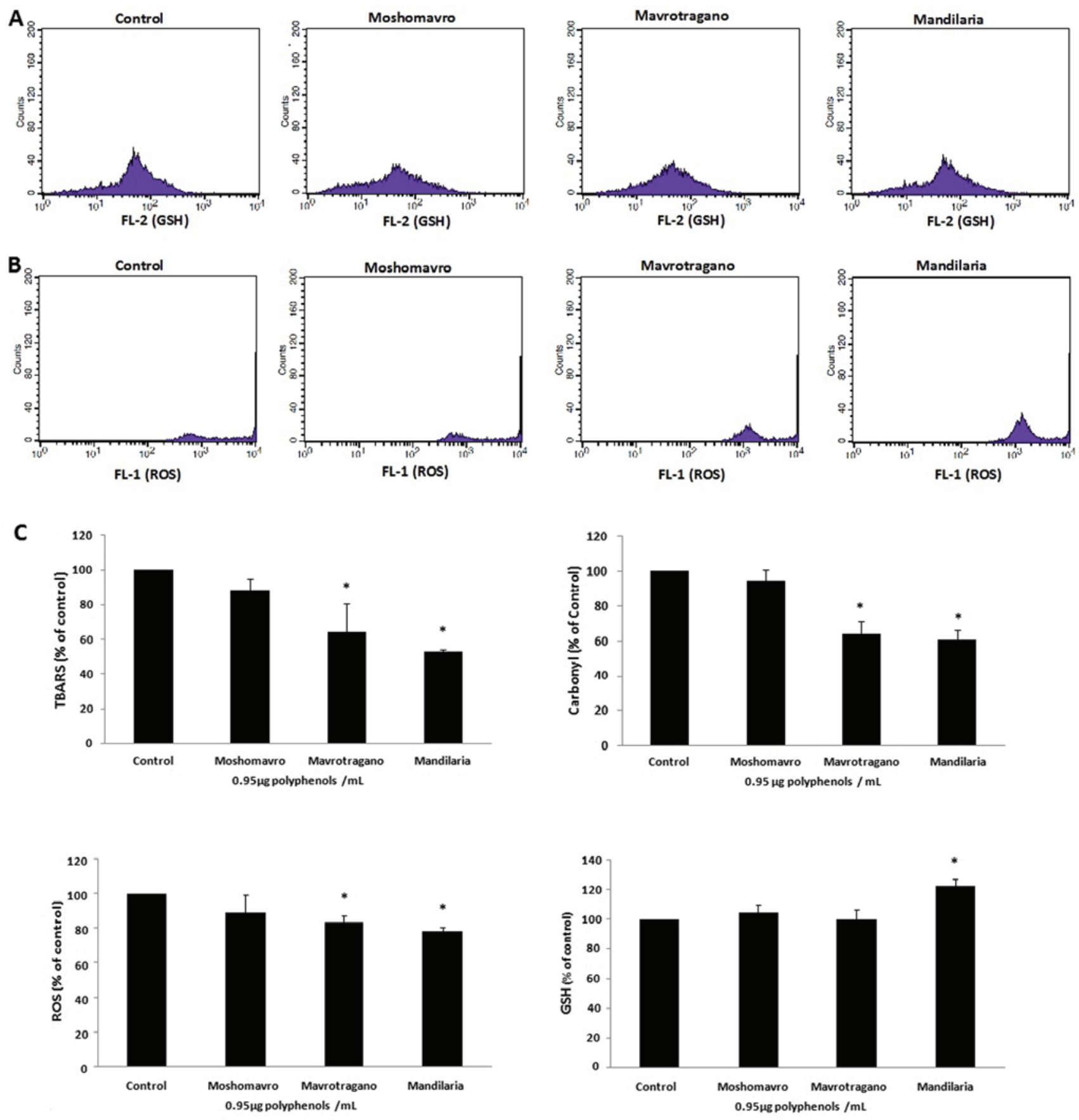

Figure 4. Effects of treatment with grape stem extracts for $24 \mathrm{~h}$ on the levels of oxidative stress markers in C2C12 cells. (A) The histogram of cell counts versus fluorescence of 10,000 cells analyzed by the flow cytometry for the detection of glutathione (GSH) levels. FL2 represents the detection of fluorescence using 488 and $580 \mathrm{~nm}$ as the excitation and emission wavelength, respectively. (B) The histograms show the cell counts versus fluorescence of 10,000 cells analyzed by the flow cytometry for the detection of reactive oxygen species (ROS) levels. FL1 represents the detection of fluorescence using 488 and $530 \mathrm{~nm}$ as the excitation and emission wavelength, respectively. (C) Effects on ROS, glutathione (GSH), thiobarbituric acid reactive substances (TBARS) and protein carbonyl (CARB) levels. TBARS and CARB levels were assessed using a spectrophotometer. All values are presented as the means \pm SEM of three independent experiments. ${ }^{p}<0.05$ indicates significant difference compared to the controls (untreated cells).

pomace $(20,31,32)$. Of note, in previous studies of ours, we demonstrated that grape stems, a by-product produced in large amounts (approximately 5\% of the original grape material) during the vinification process, which has been little investigated, contained bioactive phytochemicals and presented important biological activities $(15,24)$. In particular, we demonstrated that grape stem extracts exhibited strong antioxidant activity in vitro comparable even to that of grape seed extracts (15). In the present study, we investigated at a cellular level (i.e., in endothelial and muscle cells) the antioxidant activity of stem extracts from Greek grape varieties.

Before examining the effects of grape stem extracts on the redox status of cells, their potency of scavenging free radicals in vitro was assessed. As also demonstrated in a previous study of ours (15), in this study, the tested grape stem extracts were very potent scavengers of $\mathrm{DPPH}^{*}$ and $\mathrm{ABTS}^{++}$radicals. In both 
DPPH and ABTS assays, Mandilaria extract was the most potent and Moshomavro extract the weakest. Thus, although the three tested extracts had similar TPC values, their ability to scavenge free radicals varied greatly. Specifically, Mandilaria extract was almost 2-fold more potent as scavenger against $\mathrm{DPPH}^{*}$ and $\mathrm{ABTS}^{*+}$ radicals than Moshomavro extract. This discordance between the TPC values and free radical scavenging activity is in agreement with the results of our previous study in which the TPC values of 12 grape stem extracts had a weak correlation with their free radical scavenging activity (15). This lack of correlation between the TPC values and free radical scavenging activity suggests that the qualitative polyphenolic composition of the stem extracts may be more important than their quantitative polyphenolic content for their antioxidant potency. For example, it has been suggested that polyphenolic extracts exhibiting high antioxidant activity have a high content of special polyphenols, such as trans-resveratrol, gallic acid, quercetin, (+)-catechin, (-)-epicatechin and rutin that are very labile to oxidation, and thus can potentially scavenge free radicals before they are able to attack and damage other macromolecules (33-35). Indeed, Mandilaria extract contained at least 2-fold greater amounts of trans-resveratrol, gallic acid and quercetin than Moshomavro extract.

Moreover, the reducing power of the grape stem extracts was examined. The reducing power of a substance is associated with its antioxidant activity, since it indicates that the substances are electron donors and can reduce the oxidized intermediates of the lipid peroxidation processes, so that they can act as primary and secondary antioxidants (36). All the three grape stem extracts at increasing concentrations showed increased reducing power. As in free radical scavenging assays, Mandilaria extract exhibited the greatest reducing power, but in this case, along with Mavrotragano extract. Again, it was observed that apart from the similar TPC values of the grape stem extracts, the Mandilaria and Mavrotragano extracts had 2-fold greater reducing power than the Moshomavro extract. This difference may be attributed to the differences in the polyphenolic composition of the tested extracts. For example, a previous study reported that proanthocyanidins, a class of oligomeric flavonoids, of grape stem extracts were mainly responsible for reducing power possibly due to the relatively high number of hydroxyl groups that their monomer units contain (37).

As mentioned above, in this study, the antioxidant activity of grape stem extracts was also examined at a cellular level, specifically in endothelial and muscle cells. In a previous study, we demonstrated that grape extracts from pomace improved the redox status of EA.hy926 and $\mathrm{C} 2 \mathrm{C} 12$ cells (21). Pomace is also a by-product of the winemaking process, but it includes, apart from the stems, the seeds and skins as well. To the best of our knowledge, this is the first study on the effects of grape extracts from stems on the redox status of endothelial and muscle cells. Two of the tested extracts, the Mandilaria and Mavrotragano extracts, improved the redox status of the endothelial and muscle cells, since they reduced lipid peroxidation, as shown by the decrease in TBARS levels. Moreover, the Mandilaria and Mavrotragano extracts diminished protein oxidation, as shown by the decrease in CARB levels in the EA.hy926 and C2C12 cells. However, the Moshomavro extract was the only one of the tested extracts that did not decrease the CARB and TBARS levels compared to the untreated cells in either the EA.hy 926 or $\mathrm{C} 2 \mathrm{C} 12$ cells.

The reduction of protein oxidation and lipid peroxidation by the Mandilaria and Mavrotragano extracts may be attributed to their ability to reduce ROS levels, particularly in muscle cells. The direct free radical scavenging activity and reducing power of the Mandilaria and Mavrotragano extracts may account at least in part for their capacity to decrease ROS levels in muscle cells. On the contrary, these two extracts did not affect the ROS levels in EA.hy926 endothelial cells, possibly due to the fact that the concentrations of the extracts used in these cells were lower than those used in $\mathrm{C} 2 \mathrm{C} 12$ muscle cells. The Moshomavro extract did not alter the ROS levels in either the endothelial or muscle cells. Remarkably, Moshomavro extract was also the least potent extract in free radical scavenging and reducing power assays.

The decrease in ROS-induced damage of lipids and proteins by the Mandilaria and Mavrotragano extracts in endothelial cells may also be explained by their ability to enhance antioxidant mechanisms, such as GSH. However, in the muscle cells, only the Mandilaria extract increased GSH levels, indicating that this extract was the most potent for GSH induction. The Moshomavro extract, which did not decrease the TBARS, CARB and ROS levels was also unable to increase the GSH levels in either the endothelial or in muscle cells. The increase in GSH levels by grape stem extracts is of particular importance, since GSH, the most abundant non-protein thiol source in cells, is one of the major intracellular antioxidant molecules protecting against oxidative stress (38). In previous studies of ours, we demonstrated that GSH was a key molecule for the antioxidant activity of a grape pomace extract in both EA.hy926 and $\mathrm{C} 2 \mathrm{C} 12$ cells $(20,21)$. Specifically, grape pomace extract was shown to increase GSH levels and the expression or activity of enzymes involved in synthesis ( $\gamma$-glutamylcysteine synthetase) and metabolism (e.g., glutathione S-transferase) of GSH $(20,21)$.

As the results from the assessment of the oxidative stress markers showed, there were differences in the effects of the tested stem extracts on the redox status of the cells. These differences of the extracts were profoundly attributed to their polyphenolic composition. This conclusion is supported by the fact that the concentrations of all the three extracts had the same TPC values in the cellular experiments. Thus, it was excluded that the observed differences in the antioxidant activity between the extracts may be due to their different amount of polyphenols. Among the tested extracts, the Moshomavro extract exhibited much less potency for improving the redox status of the cells compared to the Mandilaria and Mavtotragano extracts. The Moshomavro extract also had less amounts of gallic acid, (+)-catechin, ferulic acid and trans-resveratrol than the Mandilaria and Mavtotragano extracts, and thus these polyphenols may account, at least in part, for the higher antioxidant activity of the latter two extracts. For example, a previous study demonstrated that the trans-resveratrol increased GSH levels and decreased oxidative stress-induced intracellular ROS and malondialdehyde (MDA) production in vascular smooth muscle cells (39). Gallic acid has also been shown to reduce ROS levels in vascular smooth muscle cells and their corresponding mediator $\mathrm{p} 47 \mathrm{phox}$, a molecule translocating to the membrane and inducing $\mathrm{O}_{2}{ }^{-}$production (40). Moreover, in rat vascular smooth muscle cells, ferulic acid has been shown to decrease lipid 
peroxidation and increase the activity of antioxidant enzymes (e.g., superoxide dismutase) (41). Between the Mandilaria and Mavrotragano extracts, the former exhibited more potent antioxidant activity. As regards the differences in the polyphenolic composition between these two extracts, Mandilaria had higher amounts of caffeic acid, coumaric acid, quercetin and kaempferol. Among these polyphenols, caffeic acid has been reported to decrease $\mathrm{O}_{2}{ }^{-}$levels at very low concentrations (100$1,000 \mathrm{nM}$ ) in human umbilical vein-derived endothelial cells under oxidative stress conditions (42). Furthermore, quercetin and kaempferol have been shown to reduce $\mathrm{O}_{2}{ }^{--}$levels in rat vascular smooth muscle cells through the inhibition of nicotinamide adenine dinucleotide phosphate (NADPH)-oxidase activity, the main source of $\mathrm{O}_{2}^{--}$in the vessel wall (43).

In conclusion, to the best of our knowledge, the findings of the present study indicate for the first time that grape stem extracts at low concentrations improve the redox status of endothelial and muscle cells. Therefore, grape stem extracts may be used, for instance, in the development of antioxidant food supplements used for counteracting oxidative stress-induced pathological conditions in endothelial or skeletal muscles. However, it was shown that the antioxidant activity of the grape stem extracts depended on their qualitative polyphenolic composition. For example, considerable amounts of polyphenols, such as trans-resveratrol, gallic acid, (+)-catechin, ferulic acid, caffeic acid, quercetin, coumaric acid and kaempferol may be essential for the observed antioxidant activity of the stem extracts. The knowledge of the polyphenolic composition that is responsible for a strong antioxidant activity would help to assess the quality of grape stem extracts intended for uses as antioxidant supplements.

\section{Acknowledgements}

This study was funded in part by the MSc programmes 'Biotechnology-Nutrition and Environment' and 'Molecular Biology and Genetics Applications' in the Department of Biochemistry and Biotechnology at the University of Thessaly.

\section{References}

1. Halliwell B: Free radicals and other reactive species in disease. In: Nature Encyclopaedia of Life Sciences. J. Wiley and Sons (eds). Nature Publishing Group, New York, 2001.

2. Reid MB: Free radicals and muscle fatigue: Of ROS, canaries, and the IOC. Free Radic Biol Med 44: 169-179, 2008.

3. Nunes-Silva A, Bernardes PT, Rezende BM, Lopes F, Gomes EC, Marques PE, Lima PM, Coimbra CC, Menezes GB, Teixeira MM, et al: Treadmill exercise induces neutrophil recruitment into muscle tissue in a reactive oxygen species-dependent manner. An intravital microscopy study. PLoS One 9: e96464, 2014.

4. Di Meo S and Venditti P: Mitochondria in exercise-induced oxidative stress. Biol Signals Recept 10: 125-140, 2001.

5. Deanfield JE, Halcox JP and Rabelink TJ: Endothelial function and dysfunction: Testing and clinical relevance. Circulation 115: 1285-1295, 2007.

6. Victor VM, Rocha M, Solá E, Bañuls C, Garcia-Malpartida K and Hernández-Mijares A: Oxidative stress, endothelial dysfunction and atherosclerosis. Curr Pharm Des 15: 2988-3002, 2009.

7. Higashi Y, Noma K, Yoshizumi M and Kihara Y: Endothelial function and oxidative stress in cardiovascular diseases. Circ J 73: 411-418, 2009.

8. Kokura S, Wolf RE, Yoshikawa T, Granger DN and Aw TY: Molecular mechanisms of neutrophil-endothelial cell adhesion induced by redox imbalance. Circ Res 84: 516-524, 1999.
9. Zou Y, Yoon S, Jung KJ, Kim CH, Son TG, Kim MS, Kim YJ, Lee J, Yu BP and Chung HY: Upregulation of aortic adhesion molecules during aging. J Gerontol A Biol Sci Med Sci 61: 232-244, 2006

10. Rhee SG: Cell signaling. $\mathrm{H}_{2} \mathrm{O}_{2}$, a necessary evil for cell signaling. Science 312: 1882-1883, 2006.

11. Woywodt A, Bahlmann FH, De Groot K, Haller H and Haubitz M: Circulating endothelial cells: Life, death, detachment and repair of the endothelial cell layer. Nephrol Dial Transplant 17: 1728-1730, 2002.

12. Matthaiou CM, Goutzourelas N, Stagos D, Sarafoglou E, Jamurtas A, Koulocheri SD, Haroutounian SA, Tsatsakis AM and Kouretas D: Pomegranate juice consumption increases GSH levels and reduces lipid and protein oxidation in human blood. Food Chem Toxicol 73: 1-6, 2014.

13. Kerasioti E, Kiskini A, Veskoukis A, Jamurtas A, Tsitsimpikou C, Tsatsakis AM, Koutedakis Y, Stagos D, Kouretas D and Karathanos V: Effect of a special carbohydrate-protein cake on oxidative stress markers after exhaustive cycling in humans. Food Chem Toxicol 50: 2805-2810, 2012.

14. Bagchi D, Swaroop A, Preuss HG and Bagchi M: Free radical scavenging, antioxidant and cancer chemoprevention by grape seed proanthocyanidin: An overview. Mutat Res 768: 69-73, 2014.

15. Apostolou A, Stagos D, Galitsiou E, Spyrou A, Haroutounian S, Portesis N, Trizoglou I, Wallace Hayes A, Tsatsakis AM and Kouretas D: Assessment of polyphenolic content, antioxidant activity, protection against ROS-induced DNA damage and anticancer activity of Vitis vinifera stem extracts. Food Chem Toxicol 61: 60-68, 2013.

16. Spanou C, Veskoukis AS, Stagos D, Liadaki K, Anastasiadi M, Haroutounian SA, Tsouka M, Tzanakouli E and Kouretas D: Effects of grape extracts on the in vitro activity of enzymes involved in oxidative stress regulation. In Vivo 25: 657-662, 2011.

17. Stagos D, Kazantzoglou G, Magiatis P, Mitaku S, Anagnostopoulos K and Kouretas D: Effects of plant phenolics and grape extracts from Greek varieties of Vitis vinifera on mitomycin $\mathrm{C}$ and topoisomerase I-induced nicking of DNA. Int J Mol Med 15: 1013-1022, 2005.

18. Stagos D, Kazantzoglou G, Theofanidou D, Kakalopoulou G, Magiatis P, Mitaku S and Kouretas D: Activity of grape extracts from Greek varieties of Vitis vinifera against mutagenicity induced by bleomycin and hydrogen peroxide in Salmonella typhimurium strain TA102. Mutat Res 609: 165-175, 2006.

19. Stagos D, Spanou C, Margariti M, Stathopoulos C, Mamuris Z, Kazantzoglou G, Magiatis P and Kouretas D: Cytogenetic effects of grape extracts (Vitis vinifera) and polyphenols on mitomycin C-induced sister chromatid exchanges (SCEs) in human blood lymphocytes. J Agric Food Chem 55: 5246-5252, 2007.

20. Goutzourelas N, Stagos D, Housmekeridou A, Karapouliou C, Kerasioti E, Aligiannis N, Skaltsounis AL, Spandidos DA, Tsatsakis AM and Kouretas D: Grape pomace extract exerts antioxidant effects through an increase in GCS levels and GST activity in muscle and endothelial cells. Int J Mol Med 36: 433-441, 2015.

21. Goutzourelas N, Stagos D, Demertzis N, Mavridou P, Karterolioti H, Georgadakis S, Kerasioti E, Aligiannis N, Skaltsounis L, Statiri A, et al: Effects of polyphenolic grape extract on the oxidative status of muscle and endothelial cells. Hum Exp Toxicol 33: 1099-1112, 2014.

22. Anastasiadi M, Chorianopoulos NG, Nychas GJ and Haroutounian SA: Antilisterial activities of polyphenol-rich extracts of grapes and vinification byproducts. J Agric Food Chem 57: 457-463, 2009.

23. Sahpazidou D, Geromichalos GD, Stagos D, Apostolou A Haroutounian SA, Tsatsakis AM, Tzanakakis GN, Hayes AW and Kouretas D: Anticarcinogenic activity of polyphenolic extracts from grape stems against breast, colon, renal and thyroid cancer cells. Toxicol Lett 230: 218-224, 2014.

24. Stagos D, Apostolou A, Poulios E, Kermeliotou E, Mpatzilioti A, Kreatsouli K, Koulocheri SD, Haroutounian SA and Kouretas D: Antiangiogenic potential of grape stem extract through inhibition of vascular endothelial growth factor expression. J Physiol Pharmacol 65: 843-852, 2014.

25. Kantsadi AL, Apostolou A, Theofanous S, Stravodimos GA, Kyriakis E, Gorgogietas VA, Chatzileontiadou DS, Pegiou K, Skamnaki VT, Stagos D, et al: Biochemical and biological assessment of the inhibitory potency of extracts from vinification byproducts of Vitis vinifera extracts against glycogen phosphorylase. Food Chem Toxicol 67: 35-43, 2014. 
26. Zhu L, Zhang Y, Deng J, Li H and Lu J: Phenolic concentrations and antioxidant properties of wines made from north american grapes grown in china. Molecules 17: 3304-3323, 2012.

27. Meng JF, Fang YL, Qin MY, Zhuang XF and Zhang ZW: Varietal differences among the phenolic profiles and antioxidant properties of four cultivars of spine grape (Vitis davidii Foex) in Chongyi County (China). Food Chem 134: 2049-2056, 2012.

28. Kerasioti E, Stagos D, Priftis A, Aivazidis S, Tsatsakis AM, Hayes AW and Kouretas D: Antioxidant effects of whey protein on muscle C2C12 cells. Food Chem 155: 271-278, 2014

29. Keles MS, Taysi S, Sen N, Aksoy H and Akçay F: Effect of corticosteroid therapy on serum and CSF malondialdehyde and antioxidant proteins in multiple sclerosis. Can J Neurol Sci 28 141-143, 2001.

30. Patsoukis N, Zervoudakis G, Panagopoulos NT, Georgiou CD Angelatou F and Matsokis NA: Thiol redox state (TRS) and oxidative stress in the mouse hippocampus after pentylenetetrazol-induced epileptic seizure. Neurosci Lett 357: 83-86, 2004.

31. Feringa HH, Laskey DA, Dickson JE and Coleman CI: The effect of grape seed extract on cardiovascular risk markers: A metaanalysis of randomized controlled trials. J Am Diet Assoc 111 $1173-1181,2011$.

32. Sri Harsha PS, Mesias M, Lavelli V and Morales FJ: Grape skin extracts from winemaking by-products as a source of trapping agents for reactive carbonyl species. J Sci Food Agric (In press).

33. Alov P, Tsakovska I and Pajeva I: Computational studies of free radical-scavenging properties of phenolic compounds. Curr Top Med Chem 15: 85-104, 2015.

34. Li AN, Li S, Zhang YJ, Xu XR, Chen YM and Li HB: Resources and biological activities of natural polyphenols. Nutrients 6: 6020-6047, 2014.

35. Yoshimura M: Structure elucidation of antioxidative polyphenols and their biological properties. Yakugaku Zasshi 134: 957-964, 2014 (In Japanese).

36. Chanda $S$ and Dave R: In vitro models for antioxidant activity evaluation and some medicinal plants possessing antioxidant properties: An overview. Afr J Microbiol Res 3: 981-996, 2009.
37. Karvela E, Makris DP, Kalogeropoulos N and Karathanos VT: Deployment of response surface methodology to optimise recovery of grape (Vitis vinifera) stem polyphenols. Talanta 79: 1311-1321, 2009.

38. Livingstone $\mathrm{C}$ and Davis J: Targeting therapeutics against glutathione depletion in diabetes and its complications. Br J Diabetes Vasc Dis 7: 258-265, 2007.

39. Guo R, Li W, Liu B, Li S, Zhang B and Xu Y: Resveratrol protects vascular smooth muscle cells against high glucose-induced oxidative stress and cell proliferation in vitro. Med Sci Monit Basic Res 20: 82-92, 2014.

40. Yang HL, Huang PJ, Liu YR, Kumar KJ, Hsu LS, Lu TL, Chia YC, Takajo T, Kazunori A and Hseu YC: Toona sinensis inhibits LPS-induced inflammation and migration in vascular smooth muscle cells via suppression of reactive oxygen species and $\mathrm{NF}-\mathrm{\kappa B}$ signaling pathway. Oxid Med Cell Longev 2014: 901315, 2014

41. Wu L, Li X, Li Y, Wang L, Tang Y and Xue M: Proliferative inhibition of danxiongfang and its active ingredients on rat vascular smooth muscle cell and protective effect on the VSMC damage induced by hydrogen peroxide. J Ethnopharmacol 126: 197-206, 2009.

42. Migliori M, Cantaluppi V, Mannari C, Bertelli AA, Medica D, Quercia AD, Navarro V, Scatena A, Giovannini L, Biancone L, et al: Caffeic acid, a phenol found in white wine, modulates endothelial nitric oxide production and protects from oxidative stress-associated endothelial cell injury. PLoS One 10: e0117530, 2015.

43. Jimenez R, Lopez-Sepulveda R, Romero M, Toral M, Cogolludo A, Perez-Vizcaino F and Duarte J: Quercetin and its metabolites inhibit the membrane NADPH oxidase activity in vascular smooth muscle cells from normotensive and spontaneously hypertensive rats. Food Funct 6: 409-414, 2015. 